\title{
Lugares e não lugares: travessias em A Terceira Margem do Rio e Terra Sonâmbula
}

Places and non-places: crossings in The Third Bank of the River and Sleepwalking Land

$\begin{array}{r}\text { Cristina Casagrande } \\ \text { de Figueiredo Semmelmann } \\ \hline \hline\end{array}$

1 Cristina Casagrande é doutoranda em estudos comparados de literaturas de língua portuguesa na FFLCH-USP. 
RESUMO: O artigo tem por objetivo estabelecer uma análise comparativa entre o conto A Terceira Margem do Rio, de Guimarães Rosa, e Terra Sonâmbula, primeiro romance do moçambicano Mia Couto. O tema central da análise são as travessias, lugares e não lugares presentes em ambas histórias; tanto no que diz respeito à recriação da linguagem e da construção narrativa quanto à mensagem proposta em cada uma das histórias contadas.

PALAVRAS-CHAVE: Terra Sonâmbula, A Terceira Margem do Rio, Travessias, Lugares, Não Lugares.

ABSTRACT: This article aims to stablish a comparative analysis between the tale The Third Bank of the River, by Guimarães Rosa, and Sleepwalking Land, the first novel by the Mozambican writer Mia Couto. The theme that the analysis focuses on is crossings, places and non-places in both stories; as related to remake the language and the narrative structure as to the message proposed in each one of the stories.

KEYWORDS: Sleepwalking Land, The Third Bank of the River, Crossings, Places, Nonplaces. 


\section{Introdução}

A angústia de uma família cujo pai nem parte, nem fica; um menino e um velho que caminham em círculos em meio a uma guerra civil. Uma realidade estática que gera movimento e uma narrativa em círculos que - a princípio - sempre remete ao mesmo lugar. As travessias, os lugares e não lugares de $A$ Terceira Margem do Rio e Terra Sonâmbula têm muitas semelhanças e dessemelhanças que nos movem a repensar nosso espaço no mundo.

Por travessia, entende-se o caminhar, atravessar a nado, mergulhar, gerando uma transformação no indivíduo e no grupo, desembocando em cisões, sínteses e fusões. Ora de maneira estática, ora dinâmica, a travessia sempre propicia mudança. Nessa perspectiva, abrem-se portas para o novo, para a recriação de si e do conjunto que nos cerca. No conto de Guimarães Rosa, o rio transparece imutável, mas absurdamente atraente e transformador. Por meio do linguajar complexo misturado à oralidade, com erudição e neologismos, o autor compõe a mística do conto, em que o sentido da vida e das nossas escolhas fala alto.

Em Terra Sonâmbula, a travessia é quase uma obrigação. Em um estado de guerra, depredação e morte sempre presente, para o velho Tuahir e o menino Muidinga, a única saída é continuar buscando um refúgio. Nesse contexto, a terra anda por si só, enquanto os dois andam em círculo para não se perder.

Ao contrário do conto, a terra é, a princípio, um palco maior que a água no romance do moçambicano, mas nem por isso o mar é menos atraente e transformador. O fluxo das águas é colocado com fonte de esperança e ocasião de busca pela identidade.

Por meio da comparação entre as obras, é possível conhecer esses dois autores tão importantes na construção do imaginário de Moçambique e do Brasil, falando de sua própria gente para si e para o outro. Percebemos mais sobre nós mesmos e nos descobrimos em novas culturas.

Guimarães Rosa fala de um país já independente há mais de um século, com culturas e raças miscigenadas, o arcaico e o novo colocados lado a lado. Utiliza-se da linguagem para reconstruir a identidade de um país tipicamente mestiço. Mia Couto, por sua vez, viveu a independência de seu país, que desembocou numa guerra civil e busca sua identidade em meio à multiplicidade cultural, assim como o Brasil. 
A travessia aparece nas duas obras como uma consequência natural da busca de identidade, em contato com a natureza e o povo locais. Nessa busca, o lugar e o não lugar se confundem com o objetivo de conhecer quem é o "eu” e quem é o seu povo.

A literatura se propõe a mostrar que a travessia da vida leva o povo de ambos os países ao conhecimento de si mesmo, ainda que a realidade não os leve a um lugar específico. $\mathrm{O}$ imaginário construído por cada personagem os leva a lugares metafísicos e sonhados, mas, nem por isso, irreais.

\section{Para onde levam as travessias}

Ao lermos o conto A Terceira Margem do Rio e o romance Terra Sonâmbula, podemos notar as diferentes travessias apresentadas em cada obra. Na primeira, existe o rio, que transparece uma realidade estática, angustiante, como uma opção do pai que resolve abandonar a família para viver no rio, mas sem deixá-los completamente.

No romance de Mia Couto, a terra é quem caminha. Em uma realidade sofrida pelos efeitos da guerra, andar é a única saída em busca de esperança. Em ambos os casos, de maneira mais introspectiva e estática, ou de forma coletiva e em movimento, a caminhada é ocasião de transformação. O não se decidir já é optar por algo. A travessia não depende nem sequer da realidade: estar acordado ou sonhando leva cada personagem a novas possibilidades.

As obras representam a nossa realidade, híbrida e contraditória, seja no cotidiano ou em contexto de guerra, estamos sempre vindo a ser. Ao mesmo tempo, há a busca pela nossa própria essência, seja pela identificação com os pais, ou, na esfera coletiva, pela identidade nacional.

Conforme propõe Benjamin Abdala Junior (2005), em seu texto "Fluxos comunitários: jangadas, margens e travessias", no mundo moderno, com navegações reais e virtuais, o navegador precisa obter o conhecimento dos rumos. Na literatura e em outras manifestações artísticas como cinema, o rio é o símbolo da diversidade das misturas que nos envolvem, diante disso é mister ter critério diante da demanda múltipla e frequente.

De acordo com o texto de Abdala Junior, há muitas formas de travessia na realidade e na arte: mais tranquilas, mais problemáticas, etnocêntricas, comunitárias, imaginário-míticas, 
históricas etc. Todas elas trazem novas possibilidades, transportando cada indivíduo a situações diferentes, a sonhos particulares ou a utopias sociais.

A travessia nos leva a lugares distintos, ou, até mesmo a não lugares, que configuram ambientes de passagens, locais imaginados. Segundo Marc Augé (1994), o lugar, na modernidade, sob a óptica antropológica, pode se definir como identitário, relacional e histórico, já o não lugar pode ser designado por "duas realidades complementares, porém, distintas: espaços constituídos em relação a certos fins (transporte, trânsito, comércio, lazer) e a relação que os indivíduos mantêm com esses espaços"(AUGÉ, 1994, p. 87).

Apesar de a palavra utopia, originária do grego, significar "não lugar", para o etnólogo francês, "o não-lugar é o contrário da utopia: ele existe e não abriga nenhuma sociedade orgânica" (AUGÉ, 1994), ou seja, ele pode ser um sonho individual, uma experiência pessoal. Já a ideia de utopia, segundo ele, remete a um ideal coletivo, a uma transformação social.

Ainda para Augé, a modernidade - e Guimarães e Couto fazem parte dela - produz não lugares, e eles não existem sob uma forma pura, misturando-se com lugares. "O lugar e o não-lugar são, antes, polaridades fugidias: o primeiro nunca é completamente apagado e o segundo nunca se realiza totalmente" (AUGÉ, 1994, p. 74).

Em ambas as obras rio e mar aparecem como continuidades, assim como a terra no romance de Mia Couto, ao mesmo tempo que rompe com o velho e abre espaço ao novo. $\mathrm{O}$ espaço aquático e a terra ferida pela guerra são lugares onde há mais chance para o sonho e o mundo imaginário, podendo ser configurados, de acordo com a concepção de Augé, como não lugares.

Nas duas obras que vamos analisar a seguir, mostradas como travessias, lugares e não lugares, o que permanece é o entendimento sobre nós mesmos e a realidade que nos cerca. Como propõe Benjamin Abdala Junior "as muitas margens registradas na travessia são janelas abertas para as margens do conhecimento" (ABDALA JUNIOR, 2005, p. 21). 


\section{Onde está a terceira margem?}

A interrogação não aparece aqui por acaso. O conto A Terceira Margem do Rio, de Guimarães Rosa, é cheio de dúvidas e reticências. Mas não são indagações que nos enchem de esperança e da ideia de amplidão do mundo. São dúvidas que angustiam e que nos tornam mais introspectivos.

O conto começa com "nosso pai", fazendo-nos lembrar imediatamente da oração cristã "Pai-nosso", que remete ao universo religioso e reforça a ligação familiar entre pai e filho. O pai, personagem principal do conto, resolve sair de casa, mas não propriamente abandonar a família. A angústia se dá principalmente pela não decisão: ele pega sua canoa encomendada, vai até o rio e por lá fica, não se despede de vez da família, nem retorna a ela. "Nosso pai não voltou. Ele não tinha ido a nenhuma parte" (ROSA, 2001).

O narrador-personagem é o filho mais apegado ao pai, pois se coloca na pele dele. Nessa relação, o amor passa a dar lugar a um sentimento de culpa que não se sabe exatamente por quê. O que se sabe, é que o pai parece carregar um fardo que está ali, naquele rio, dentro daquela canoa. E que o filho passa, por hereditariedade, tal qual o pecado original, segundo a teologia cristã, a ser responsável por aquele triste fardo também.

Se tem o dever de expiar alguma culpa, o pai não cumpre a tarefa, tampouco a negligencia. Não vai para a margem da volta, do arrependimento, nem para a da fuga: a terceira margem do rio é o próprio rio, que faz aquele homem ter um encontro consigo mesmo e com seus próprios "eus", frutos da transformação que gera aquele universo fluvial.

Naquela situação, as palavras já não tinham mais lugar, só o silêncio e os gestos diziam algo. Com o olhar, o pai chama o filho para mostrar aonde vai, para que ele já sabe a via-sacra pela qual vai passar. Mas com o mesmo olhar, pede para que o filho fique, o pai vai cumprir a sua pena sozinho.

A travessia é, paradoxalmente, estática, pois o pai não se move tampouco o rio onde ele passa a habitar, mas, ainda assim, causa mudanças. Se o pai não volta nem parte, a família acaba se mudando, um a um, até sobrar o filho, que narra a história. Cada um se esvazia de si: ao abandonar o pai, ocorre uma cisão com a família, um prenúncio da morte. Segundo Walnice Galvão (2008), no texto "Do lado de cá”, que traz uma análise do célebre conto rosiano, 
a terceira margem vai além do mistério da morte, própria de cada um, mas que ninguém partilha essa experiência, pois é única e intransferível.

O mistério do rio propicia o encontro com o próprio eu e sua existência. A terceira margem, o rio, é a eterna busca por um sentido da vida. Recorda a ensaísta que "na linguagem cifrada das religiões é frequente o símbolo da praia, ou margem, ou terra firme aonde se chega quando se morre" (GALVÃO, 2008, p. 43).

No entanto, a experiência é constante angústia, o rio se torna um beco sem saída. "Nada aqui, neste texto, de promessa de uma outra vida depois da morte, nem de vida eterna, nem de recompensas para os bem-comportados. Apenas o espanto e o pânico ante o que não é" (GALVÃO, 2008, p. 43). O rio, portanto, leva o pai e o filho a um não lugar, não tem onde ficar, nem onde partir. O restante da família, por sua vez, se muda, busca uma identidade, longe da figura paterna, um ente conflituoso.

O pai, ao não tomar uma decisão, porém, já faz a sua escolha: não querer mudar e, com isso, muda a si mesmo e tudo à sua volta. No momento em que o pai envelhece, o filho sente que chega a sua hora de trocar de lugar com ele. Naquela situação de solidão e abandono, ambos estão, cada qual, em um não lugar. A mudança, então já não se faz mais necessária. Tal como o pai, o filho não fugiu nem ficou, deixou que a maré da vida o guiasse. De acordo com Walnice Galvão, tal decisão ou indecisão corresponde ao fato de não querer encarar a vez de morrer.

Ambos, pai e filho, se assemelham em quase tudo, mas se diferenciam fortemente em um ponto crucial: o pai deixou descendentes e a ideia de continuidade de sua história - tem filho e tem neto, fruto do casamento de sua filha. O filho, no entanto, se não casou, nem teve filhos.

O pai, tal como rio, escolheu a continuidade como seu não lugar existencial. O filho é como a canoa fabricada do pai, escolheu a descontinuidade e ficou à deriva das decisões silenciosas e inexplicáveis de seu progenitor. Nesse desfecho, a relação pai e filho se dá pela imitação (a não decisão) e pela ruptura, ao negar as decisões do pai, como a canoa descontínua, por optar por não deixar descendentes, nenhum legado da sua miséria ${ }^{2}$.

2 Referência à famosa frase de Brás Cubas, personagem de Machado de Assis: "Não tive filhos, não transmiti a nenhuma criatura o legado da nossa miséria”. (in Memórias Póstumas de Brás Cubas). 


\section{Palavras que cruzam os sonhos}

"Perguntar pra onde se está indo é típico de quem não sabe onde está" (AUGÉ, 1994, p. 105). Já no início de Terra Sonâmbula, o menino Muidinga pergunta ao velho Tuahir onde estão e para onde vão. O velho e o garoto não estão em lugar nenhum - em um não lugar - e tampouco sabem aonde vão.

Mas o quadro angustiante não para por aí: Muidinga não sabe quem ele é, quem são seus pais, de onde veio, qual a sua relação com o "tio" Tuahir, nem mesmo qual seu verdadeiro nome. Além de estar em um não lugar, o menino tem uma não identidade, sem passado, presente ou futuro certos. Essa aflição não tem fim, enquanto ele não tiver um porto onde ancorar. "O passageiro dos não lugares só encontra sua identidade no controle da alfândega no pedágio ou na caixa registradora" (AUGÉ, 1994, p. 95).

Em seu itinerário, encontram um machimbombo (ônibus), símbolo da viagem, que está queimado, cheio de cadáveres carbonizados. O velho, que toma o menino como seu próprio filho, pois já não tem mais família, resolve enganar o garoto. Finge que estão indo adiante, mas resolve andar em círculos, sempre retornando ao ônibus queimado. Isso ocorre para que eles não se percam, embora nunca encontrem um lugar certo - "a volta ao lugar é o recurso de quem enfrenta os não-lugares" (AUGÉ, 1994, p. 95).

Próximo ao machimbombo, Muidinga encontra um corpo morto há pouco tempo, que fora atingido por armas de fogo. Com ele, existem alguns cadernos de anotações, contando sua história. Assim o garoto e Tuahir conhecem o cadáver de Kindzu, um jovem que deixou a casa após a morte do pai e desejava se tornar um naparama, um guerreiro de paz.

Nesse momento, os cadernos de Kindzu passam a ser companhia e sonho de Muidinga - mais tarde, de Tuahir também. O acesso a outro mundo alheio ao seu, traz esperanças a Muidinga. A partir de então, o garoto frequenta dois não lugares: o da terra ferida por onde caminha ao léu e o das anotações de um homem recém baleado. Mundo real e imaginário se confundem e se fundem, até trocarem de posição: ao final do livro, o autor sugere que Muidinga é Gaspar, o filho de Farida, amante de Kindzu.

De acordo com a tese de doutorado de Rejane Vecchia da Rocha Silva (2000), Romance e Utopia - Quarup, Terra Sonâmbula e Todos os Nomes, as lembranças só aparecem em sonhos, 
espaço da utopia. Assim, Muidinga e Tuahir, ao sonhar com os cadernos de Kindzu apresentam uma fuga diante da impossibilidade da vida. "O sonho é o espaço em que o lugar ideal se apresenta" (SILVA, 2000, p. 127).

O romance é escrito ao final da guerra civil moçambicana, seguida da guerra da independência. No romance, Mia Couto, segundo Silva, tem o sonho da construção da verdadeira história de Moçambique, um país miscigenado e dolorido pelas guerras, que busca sua identidade.

"Moçambique, ao mesmo tempo em que é descrito com espaço de perdas, de abandono e da ausência do humano, também se coloca na região de utopias e sonhos" (SILVA, 2000, p. 134). Um pouco diferente da concepção de Marc Augé sobre utopia, Silva discorre sobre essa ideia do ponto de vista da narrativa. "A utopia, que é o desejo do sonho e da vida, surge dentro de uma narrativa que, às vezes, recorre ao fantástico para mostrar a brutalidade da realidade frente aos maiores absurdos criados pela ficção" (SILVA, 2000, p. 132).

Mas o sonho está imbricado à realidade, o próprio título do romance nos leva a essa conclusão, Terra Sonâmbula, dando a ideia de que o lugar onde eles estão caminha sonhando. Assim a travessia é quem protagoniza esse mundo de sonhos. "O problema não é o lugar e sim o caminho" (COUTO, 2007, p. 31).

No romance, as duas histórias levam a caminhos distintos que se convergem. Assim, o caminho a se preocupar é tanto o da terra ferida pela guerra, quanto o das letras descritas por Kindzu. Em seus cadernos, o aventureiro descreve traços da cultura de seu país. Ironicamente, o mundo real parece menos tangível que o mundo da literatura para Muidinga.

Os cadernos de Kindzu são não lugares sonhados para Muidinga e o Tuahir, espaço para utopia, tornando-se mais real que a própria realidade que os cerca. "A palavra, aqui, não cava um fosso entre a funcionalidade cotidiana e o mito: ela cria a imagem, produz o mito e, ao mesmo tempo, o faz funcionar" (AUGÉ, 1994, p. 88).

Kindzu, por sua vez, também trazia sonhos consigo, como virar um naparama, guerreiro da paz, ou trazer o filho de Farida, Gaspar, de volta. Sonhando os anseios de Kindzu, Muidinga larga tudo para viver aquela história, até descobrir que faz parte dela, como sugere o livro no final. "Então, as letras, uma por uma, se vão convertendo em grãos de areia e, aos poucos, todos meus escritos vão se convertendo em páginas da terra" (COUTO, 2007, p. 204), diz o desfecho de Terra Sonâmbula. 
A terra proporciona sonhos e a água, o mar, é símbolo da fusão entre o sonho e realidade. Ao buscar um feiticeiro sábio em sua terra, Kindzu ouve que sua cura se dará pelo mar, justamente para onde seu pai se foi e não mais voltou. Tuahir também buscou o mar como redenção e libertação, pedindo a Muidinga que o empurrasse dentro de um barco - cujo nome era Taímo, como se chamava o pai de Kindzu - para as ondas do mar.

No encontro com Nhamataca, amigo de Tuahir, que quer construir um rio, há um prenúncio sobre os feitos da água, símbolo da esperança, em ambas as histórias contadas. "As águas haveriam de nutrir as muitas sedes, confeitar peixes e terras. Por ali viajariam esperanças, incumpridos sonhos. E seria o parto da terra, do lugar onde os homens guardariam, de novo, suas vidas" (COUTO, 2007, p. 86).

\section{Através do Atlântico}

Segundo Silvana Núbia Chagas (2006), tanto Guimarães Rosa quanto Mia Couto têm o projeto estético de recriação da tradição oral na estrutura narrativa. Brasil e Moçambique, de onde se originam e se ambientam o conto de Rosas e a novela de Couto respectivamente, são países distintos e distantes, mas com algumas características comuns, como a língua portuguesa oficial, a presença de outras línguas que se misturam com o português e compõem o vocabulário, além de serem ambos altamente miscigenados, sem uma identidade nacional evidente. Isso posto, nas obras em questão, os autores buscam a literatura como forma de recriação da linguagem, mais do que um resgate à tradição ou à identidade.

Reforçando a questão, conforme relata Rita Chaves (1997), Couto conheceu Rosa por meio do ficcionista angolano Luandino, e segundo o autor moçambicano, a obra do mineiro confirmaria a legitimidade do caminho que Couto percorria.

Pode-se dizer que, nas trilhas do autor do Grande sertão e do cantador dos musseques de Luanda, o contista moçambicano viu na reinvenção da língua portuguesa uma fonte para contar o mundo vasto e movimentado de um país onde a noção de identidade se nutre nas águas caudalosas de uma impressionante diversidade cultural (CHAVES, 1997, p. 243). 
Ambos autores, de lugares e épocas distintas teriam como outro fato incomum estar inseridos na modernidade. "Como se sabe, a escritura de Guimarães Rosa é pautada pelo que se postulou chamar 'modernidade' (...) e os países africanos não se pautam nessa cultura. No entanto, sabe-se que Mia Couto rompe com a estética literária de seu país, a sua escrita faz parte da literatura moderna" (CHAVES, 1997, p. 14).

Não se pode falar de comparação entre Couto e Rosa sem falar de oralidade. "Os dois autores remetem ao hibridismo cultural que permeia os dois países. A única diferença (...) é que, para Rosa, a tradição oral já fazia parte do passado e, para Mia, é algo que faz parte do cotidiano" (CHAVES, 1997, p. 89).

Ao comparar, especificamente, Terra Sonâmbula e A Terceira Margem do Rio sob a óptica de travessia, lugares e não lugares, já observamos algumas semelhanças e diferenças. No conto do modernista brasileiro, a travessia, embora se dê, preponderantemente, pelas águas, é estática e metafórica. O lugar é um não lugar, pois nunca é definitivo. Em Terra Sonâmbula, a travessia é ambulante e circular, com preponderância na terra (embora o contato com o mar seja frequente), um meio estático, o não lugar (cadernos de Kindzu), é lugar definitivo no imaginário de Muidinga.

Em ambas as obras, há a angústia do ir e do ficar. No conto, a aflição se dá pelo abandono (não definitivo) do pai, que carrega um fardo inexplicável sozinho. No romance, a discussão entre o ir e ficar é explicitada na interação Kindzu - que quer partir - e Farida - que quer ficar. "As personagens sofrem com o distanciamento de suas origens, com a possibilidade de perder seus poucos referenciais. Há um sentimento ambíguo entre ficar e fugir" (SILVA, 2000, p. 135).

Kindzu é o típico personagem que não pertence a lugar nenhum, por isso está sempre em busca de si mesmo. Ele representa a humanidade, mais do que um povo sem pátria. A relação com Surendra Valá, o indiano, é fluida e sincera, porque cada um enxerga no outro um sujeito, uma pessoa, sem competitividade, nem desmerecimento. Diz o indiano ao aspirante a naparama: "Eu gosto de homens que não têm raça, é por isso que eu gosto de si, Kindzu" (COUTO, 2007, p. 28).

Dentre as semelhanças entre os contos, a mais óbvia é a ausência da figura paterna, ao desaparecer rumo ao fluxo das águas. A figura paterna está intrinsecamente ligada à travessia, 
pois o pai simboliza a origem de onde partimos, nos faz lembrar quem somos, e é o modelo de quem seguir os passos, de saber aonde vamos.

O personagem de Rosa não morre, mas abandona a família para morar no rio, causando uma amargura na família maior do que se tivesse morrido. Taímo, pai de Kindzu, morre de desgosto, depois do sumiço do filho mais novo, Junhito, agarrado ao barco, junto ao mar. Tuahir, que acompanha Muidinga desde o início da narrativa, também exerce uma figura paterna, e assim como os outros, entrega-se ao mundo das águas.

O pai, no conto, é constante presença - pela ausência - ao narrador-personagem. Taímo se faz presente a Kindzu pelo sonho, e é ele que guia o rapaz em buscas de mudanças, ao mesmo tempo em que o repreende da fuga de casa. Em busca pela cura no mar, Kindzu sabe que não pode se esgotar nele, se ainda quiser estar em contato com a realidade. "A terra está carregada de leis, mandos e desmandos. O mar não tem governador. Mas, cuidado, filho, a pessoa não mora no mar" (COUTO, 2007, p. 32).

Ambas as histórias — ou estórias — deixam o seu recado frente às travessias da vida. No habitar da terra, Tuahir e Kindzu estão à margem, assim como a família está em $A$ Terceira Margem do Rio. Na ficção moçambicana, o andar é primordial para voltar sempre ao mesmo ponto, enquanto no conto brasileiro, ficar parado já é trocar de lugar, que é um não lugar.

Diferente do conto de Guimarães Rosa, Terra Sonâmbula termina com ares de esperança - a travessia abriu-se para o novo. O jovem Kindzu cumpre sua missão ao tornar-se um naparama e aparentemente ter encontrado o menino Gaspar (Muidinga), ainda que tudo possa ter acontecido na esfera onírica. No conto, a angústia permanece do início ao fim, restando-nos apenas nos consolarmos com a imaginação, na hipótese de que tudo fosse diferente — a travessia do rio era um fardo pesado e inexorável.

E se o narrador, filho do homem que larga a família para permanecer no rio, tivesse trocado de lugar? Será que somos todos fadados à covardia? Foi covarde o pai? O romance de Mia Couto via em um sentido diverso. A morte de Kindzu não é uma tragédia típica, pois que permite haver um novo começo, de um país - Moçambique - que finalmente estaria para nascer. Ao passo que o Brasil, já independente há anos, estaria ainda em busca de uma tomada de decisão mais ativa e menos estática, com novos rumos para a construção de nossa história. 


\section{Referências Bibliográficas}

ABDALA JUNIOR, Benjamin. Fluxos comunitários: jangadas, margens e travessias in Literatura comparada relações comunitárias hoje. São Paulo: Revista Via Atlântica, 2005.

AUGÉ, Marc. Não-lugares: Introdução a uma antropologia da supermodernidade. Campinas, SP: Papirus, 1994.

CHAGAS, Silvana Núbia. Nas Fronteiras da Memória: Guimarães Rosa e Mia Couto, olhares que se cruzam. São Paulo: Tese de Doutorado FFLCH-USP, 2006.

CHAVES, Rita. Mia Couto: Voz nascida da terra. Novos Estudos, n. 49, p. 243-256, nov. 1997.

COUTO, Mia. "Rosa em Moçambique" in E se Obama fosse africano? São Paulo: Companhia das Letras, 2007.

COUTO, Mia. Terra Sonâmbula. São Paulo: Companhia das Letras, 2007.

GALVÃO, Walnice Nogueira. Minima mímica: ensaios sobre Guimarães Rosa. São Paulo: Companhia das Letras, 2008.

ROSA, João Guimarães. Primeiras Estórias. Rio de Janeiro: Nova Fronteira, 2001.

SILVA, Rejane Vecchia da Rocha. Romance e Utopia - Quarup, Terra Sonâmbula e Todos os Nomes. São Paulo: Dissertação de Doutorado FFLCH-USP, 2000. 